\title{
BLOCH NA AMÉRICA LATINA AS RAÍZES ÉTICAS DA FILOSOFIA DA ESPERANÇA*
}

Anna Maria Lorenzoni ${ }^{1}$

\begin{abstract}
Resumo:
No presente artigo, busca-se fazer uma breve reconstrução dos percursos históricos e teóricos que permitiram o acolhimento e a apropriação de conceitos fundamentais da filosofia blochiana no interior das inquietações sociais latino-americanas, bem como destacar as particularidades das interpretações difundidas no Brasil. Tendo como fio condutor a busca dos elementos éticos da filosofia blochiana, o percurso se inicia com uma contraposição entre as literaturas secundárias a respeito do autor disponíveis no Brasil e na Alemanha. A ambiguidade entre a manifesta importância dos pressupostos éticos da filosofia da esperança enfatizada pelos comentadores brasileiros contraposta ao papel secundário atribuídos pelos comentadores alemães é, então, explorada a partir de um rastreamento dos caminhos que trouxeram a filosofia blochiana até o continente latino-americano. A despeito do ateísmo do filósofo alemão, na América Latina, a filosofia da esperança aliou-se à "herética" teologia da libertação, sendo essa a sua porta de entrada principal. Aqui, a filosofia de Bloch se confunde e entrecruza com a própria história do marxismo e do cristianismo no continente, repercutindo na originalidade dos movimentos sociais e das bases éticas que os orientam. A utopia, tal qual concebida pelo autor, revela-se como ponto de encontro fundamental entre a fé e a política.
\end{abstract}

Palavras-Chave: Cristianismo. Filosofia e Teologia da Libertação. Marxismo. Movimentos Sociais. Utopia.

\section{BLOCH IN LATIN AMERICA THE ETHICAL ROOTS OF THE PHILOSOPHY OF HOPE}

\begin{abstract}
:
In this article, we seek to make a brief reconstruction of the historical and theoretical paths that allowed the reception and appropriation of fundamental concepts of Blochian philosophy within Latin American social concerns, as well as highlighting the particularities of the interpretations spread in Brazil. Taking as a guiding thread the search for the ethical elements of Blochian philosophy, the journey begins with a contrast between the secondary literatures about the author available in Brazil and in Germany. The ambiguity between the manifest importance of the ethical assumptions of the philosophy of hope emphasized by Brazilian commentators, as opposed to the secondary role attributed by German commentators, is then explored through a tracking of the paths that brought Blochian philosophy to the Latin American continent. In spite of the German philosopher's atheism, the philosophy of hope has allied itself with the "heretical" liberation theology in Latin America, which is its main gateway. Here, Bloch's philosophy is confused and intertwined with the history of Marxism and Christianity on the continent, reflecting on the originality of social movements and the ethical bases that guide them. Utopia, as conceived by the author, reveals itself as a fundamental meeting point between faith and politics.
\end{abstract}

Keywords: Christianity. Liberation Philosophy and Theology. Marxism. Social movements. Utopia.

Ernst Bloch não escreveu trabalhos específicos sobre o tema da ética, mas isso não

\footnotetext{
O presente trabalho foi realizado com apoio da Coordenação de Aperfeiçoamento de Pessoal de Nível Superior - Brasil (CAPES) - Código de Financiamento 001.

1 Doutora em Filosofia pela Universidade Estadual do Oeste do Paraná (Toledo, 2015-2019), com estágio de pesquisa (doutorado sanduíche) na Universität Koblenz-Landau em parceria com o Ernst-Bloch-Zentrum, de Ludwigshafen, na Alemanha, sob supervisão da Prof. Dra. Francesca Vidal (Landau in der Pfalz, 2017-2018). Dedica-se ao estudo da obra de Ernst Bloch, sobretudo seus aspectos éticos e políticos e sua recepção na América Latina. Endereço para contato: annamlorenzoni@gmail.com.
} 
significa necessariamente que sua concepção de mundo não tenha motivações éticas fundamentais, ou ainda, que o autor não tenha se indagado sobre os melhores modos de agir no mundo. De fato, na literatura dedicada aos estudos sobre o autor no Brasil, parece não haver dúvidas de que sua filosofia tem um pressuposto eminentemente ético, não obstante não haja uma unanimidade quanto ao conteúdo ou significado dessa ética, que ora se assemelha a imperativos morais, ora a modos de vida que reivindicam compreensão. É interessante observar que, apesar de na literatura brasileira secundária sobre Bloch haver um consenso quanto à existência de uma ética blochiana, seus estudiosos não se aprofundaram abundantemente na questão, e, de fato, não parece haver um acordo, ou esclarecimento, sobre o que cada autor considera como "ética" para Bloch.

Albornoz (2006), por exemplo, não faz uma distinção clara entre ética e moral, ora afirmando que a filosofia blochiana da utopia culmina em uma ética da transformação "importa transformar" -, ora declarando, sobretudo, que Bloch estabelece uma norma geral omnia sunt communia - como condição para alcançar a sociedade sem classes. Vieira (2010), por outro lado, interpreta a ética blochiana a partir da perspectiva da filosofia da libertação, compreendendo que a filosofia de Bloch é, embora não explicitamente, fundamentalmente ética, porque tem como objetivo final a libertação do ser humano, isto é, a realização de uma sociedade justa. Bicca (1987), apropriando-se da interpretação blochiana de Marx, sustenta que há um valor implícito no pensamento de Marx (aclamado por Bloch) que se configura como o ideal do summum bonum, o Bem Supremo; concebido no materialismo histórico-dialético, esse ideal adquire, segundo o comentador, a importância de ser o telos ou o sentido da história geral humana, mas pondera que ele pode ser alterado. Semelhante a Bicca, Münster (1993) percebe que, através da ligação do conceito de utopia com o de esperança crítica [docta spes] - que visa a negação de todas as relações humanas baseadas na alienação e na dominação -, está implicada uma reformulação da questão ética; não no sentido de uma ética normativa tradicional, mas no sentido da reivindicação da realização de uma nova prática humana e moral. Segundo o comentador alemão, famoso e traduzido no Brasil ${ }^{2}$, Bloch acredita nas possibilidades reais da concretização de um ser utópico a partir de uma realidade negativa e na humanização final do mundo através da "ressurreição da natureza" e do advento do "reino da liberdade", mas deseja, sobretudo, que o processo de criação de ideais seja compreendido.

Sendo assim, parece possível dividir os comentários à filosofia de Bloch,

2 Apesar de ser o único estrangeiro de nossa lista de referências, Münster possui uma série de trabalhos sobre Bloch traduzidos e publicados no Brasil, amplamente citado nas bibliografias brasileiras consultadas, por isso julgamos pertinente inseri-lo entre as interpretações hegemônicas no país. 
disponíveis no Brasil, em duas linhas interpretativas. A primeira delas, sublinhando que o conteúdo ético blochiano diz respeito a uma postura frente ao mundo (Albornoz e Vieira), enquanto a segunda enfatizaria o conteúdo último para o qual a humanidade se inclinaria (Bicca e Münster) ${ }^{3}$. Em comum, essas interpretações enfatizam o papel de Marx naquilo que seria a ética blochiana, e tal origem marxiana do elemento ético seria a responsável por impulsionar o ser humano na transformação da realidade opressiva que o circunda. Deslocando o olhar para um contexto alemão, em vez disso, é possível notar uma abordagem pouco centrada nos potenciais aspectos éticos da filosofia blochiana, sugerindo que a problemática ocupa um papel periférico nas discussões da literatura secundária sobre o autor desenvolvidas fora da América Latina.

No cenário germânico, já a leitura do verbete dedicado à ética no Dicionário Bloch [Bloch-Wörterbuch] chama atenção ao fato de que, nesse contexto, o tema da ética blochiana não parece ser tão central como ocorre na América Latina. De modo geral, os intérpretes alemães tendem a alegar barreiras metodológicas que dificultariam a reconstrução de tal ética. Schiller (2012), por exemplo, encerra esse verbete com o alerta de que o emprego incessante de nomes, citações e associações torna difícil identificar o contexto conceitual ou a estrutura argumentativa da ética blochiana e reconstruí-la. Segundo o autor, Bloch se deixaria levar pela emoção de sua própria eloquência, de modo que transpareceria que a contemplação ou reflexão crítica não seria algo desejável. Isso significaria, ainda de acordo com o Dicionário, que a ética blochiana talvez não seja realmente envolvente, nem mesmo mais importante, que a de Hegel, Kant e Marx, por exemplo. De fato, é admirável a riqueza de conhecimento do filósofo alemão, e, segundo Schiller, dever-se-ia reconhecer a perspectiva histórico-cultural examinada por Bloch entre seus pares do século vinte. Essa riqueza, contudo, muitas vezes possuiria alguns aditivos e superficialidades, de maneira que se arrastaria para um turbilhão de metafísicas utópicas cujo princípio esperança não poderia, por si só, determinar - "a coisa real ainda não encontrada", “o fim último do desejo”, “o melhor”, “aquilo que não devemos esquecer”, nessa perspectiva, não seria especificável ${ }^{4}$.

Esses não são os únicos comentadores lidos no Brasil, mas sem dúvida são referências para aqueles que estudam Bloch. Além deles, veja-se também: FURTER, Pierre. Dialética da esperança. Rio de Janeiro: Paz e Terra, 1974 e DUSSEL, Enrique. Ética da Libertação - na idade da globalização e da exclusão. Tradução de Ephraim, F. Jaime. Petrópolis-RJ: Vozes, 2000, este último, apesar de não possuir trabalhos específicos sobre Bloch, frequentemente recorre a ele para fundamentar sua ética da libertação.

4 Em publicação precedente, Schiller, o autor do verbete supracitado, explicitou uma interpretação diversa da publicada no Dicionário Bloch, indicando a sociedade sem-classes como o summum bonum explícito da filosofia de Bloch. Sobre tal consideração, elaborada por meio de uma análise das críticas de Hans Jonas ao conceito de utopia de Bloch, veja-se: SCHILLER, Hans-Ernst. Ethik und Kritik der Utopie. Zum Verhältnis von Ernst Blochs Veränderungsethik und der Erhaltnungsethik von Hans Jonas. In.: DECKER, Oliver; GRAVE, Tobias (Hrg.). Kritische Theorie zur Zeit - Für Christoph Türcke zum sechzigsten Geburtstag. 
Essa interpretação destoa significativamente daquela que Dussel (2013, p. 335 tradução nossa) dá, por exemplo, em seu tratado de ética:

\begin{abstract}
Frequentemente considerado como metafórica, ambígua e idealista, a obra de Bloch agora pode ser claramente vista como situada exatamente no momento positivo da projeção (como afeto e razão) do possível, das alternativas ainda-não-realizadas. Mas a posição utópica de Bloch seria ininteligível se não fosse abordada a partir da perspectiva de seu conteúdo (Inhalt ou Material com "a"). Isso é o que permanece obscuro para os críticos e comentadores da obra de Bloch. [...] Como em toda ética material, o tema inicial da obra de Bloch é a vida.
\end{abstract}

$\mathrm{O}$ argentino Enrique Dussel faz tais afirmações tomando como parâmetro $O$ Princípio Esperança e, efetivamente, a obra-prima de Bloch tem servido como referência basilar para os estudos dos pesquisadores latino-americanos, especialmente os brasileiros. Tendo isso em vista, mostra-se pertinente observar os comentários alemães ao que ela representa filosoficamente, e dar atenção sobretudo às ponderações feitas a respeito da quinta parte da obra, especialmente os capítulos 54 e $55^{5}$, nos quais a temática é abordada abertamente por Bloch - e que representam o ápice argumentativo de nossa tese. Dois "manuais" para a leitura de $O$ Princípio Esperança cumprem manifestadamente esse papel - um publicado em 1977 e outro publicado em 2017.

Subdividido em categorias temáticas, Materialien zu Ernst Blochs «Prinzip Hoffnung» (SCHMIDT, 1977) possui um item chamado Zu Ethik und Rechtsphilosophie, no qual, curiosamente, encontram-se dois artigos, um sobre política e outro sobre filosofia do direito, mas nenhum especificamente sobre ética ${ }^{6}$. Não obstante os conceitos de "Das Beste", "höchste Ziel", "humanum" orbitem em ambos textos, qualquer alusão à uma possível ética blochiana não passa de um pressuposto subentendido, porém nunca explicitado diferentemente do que ocorre entre os textos latino americanos, por exemplo. Mais atento às nuances interpretativas da ética blochiana, em vez disso, é o artigo de Dolf Sternberger, Vergi $\beta$ das Beste nicht!, publicado na seção Über Blochs Sprache und Denkstil da obra supracitada ${ }^{7}$. Nele, o autor sugere que os pressupostos éticos blochianos a respeito do que é o melhor, ou ao

Leipzig: Klampen Verlag, 2008, p. 56-69.

5 Capítulo 54: Der letzte Wunschinhalt und das höchste Gut (p. 1551-1602) [O conteúdo último do desejo e o bem supremo, p. 396-439 da edição brasileira], e Capítulo 55: Karl Marx und di Menschlichkeit: Stoff der Hoffnung (p. 1602-1628) [Karl Marx e o espírito humanitário; substância da esperança, p. 440-457 da edição brasileira].

6 São eles: von KEMPSKI, Jürgen. Bloch, Recht und Marxismus [1964]. In: Materialien zu Ernst Blochs »Prinzip Hoffnung«. Frankfurt am Main: Suhrkamp, 1977, p. 367-372, e VALDES, Ernesto Garzon. Die Polis ohne Politik [1963]. In: Materialien zu Ernst Blochs »Prinzip Hoffnung «. Frankfurt am Main: Suhrkamp, 1977 p. 372-387.

7 Cf: STERNBERGER, Dolf. Vergiß das Beste nicht! In: SCHMIDT, Burghart (Hrsg.). Materialien zu Ernst Blochs »Prinzip Hoffnung«. Frankfurt am Main: Suhrkamp, 1977, p. 147-159. 
menos do que não deve ser esquecido na práxis, estão intimamente ligados aos meios teóricos pelos quais o autor expõe sua filosofia. Ainda segundo Sternberger, apesar de Bloch ser um utópico - e não um moralista -, sua obra magna se orienta a partir de um tema e suas variações - do mesmo modo que uma sinfonia ou uma sonata - em direção a uma meta de cunho humanista estreitamente ligada ao marxismo - "Não esquecer o melhor", nessa perspectiva, seria como um prelúdio para o anúncio de uma Heimat concretamente possível.

Já na publicação alemã mais recente a respeito de $O$ Princípio Esperança - Ernst Bloch: Das Prinzip Hoffnung - Zimmermann (2017) organiza uma espécie de guia para a leitura da obra magna de Bloch, cuidadosamente dividido de acordo com capítulos individuais, grupos de capítulos e partes da mesma, de modo que as articulações entre elas iluminam certas questões estruturantes que reverberam nesta investigação sobre o tema da ética em Bloch. Entretanto, apesar de seus autores parecerem concordar com a interpretação de que aquilo que Bloch considera como "o melhor" [das Beste] mescla-se e muitas vezes confunde-se com os diagnósticos que o autor realiza ao se debruçar sobre a história das utopias, algumas observações parecem colocar sob suspeita posturas éticas blochianas que, durante a leitura de sua obra, soam como convicções do filósofo alemão. De fato, Müller-Schöll e Vidal (2017, p. 359) sustentam que, devido aos eventos dramáticos da época de sua publicação, as afirmações contidas no último capítulo da obra - Karl Marx e o espírito humanitário; substância da esperança - seriam provisórias e pouco homogêneas, sendo, de um ponto de vista filosófico, simples resumos e repetições de certas partes da obra. Isso colocaria sob suspeita as posições blochianas mais enfáticas a respeito de uma "Heimat comunista", já que isso poderia ser um mero artifício para que a obra pudesse ser divulgada e publicada sem maiores problemas para seu autor ${ }^{8}$.

Ainda que as ambiguidades sobre a centralidade da temática ética no interior da filosofia blochiana pareçam circunscrever-se aos "locais de fala" de seus intérpretes 9 , é notável

8 As autoras fazem referências às revisões pelas quais as publicações blochianas passaram no período no qual o autor trabalhou em Leipzig, na República Democrática Alemã, e que explicariam certas ênfases de cunho marxista-leninista, inseridas na redação final do texto apenas após uma coação externa vinda do partido oficial. Sobre o período no qual Bloch viveu na Alemanha Oriental, veja-se: von AMBERGER, Alexander. Ernst Bloch in der DDR - Hoffnung - Utopie - Marxismus. In.: Deutsche Zeitschrift Für Philosophie (DZPhil), Akademie Verlag, Band 61, Heft 4, Oktober 2013, p. 561-576. Bloch era manifestadamente um marxista, mas, talvez, ter que "colocar seu marxismo à prova" não teria sido algo tão pertinente para o autor caso ele se encontrasse em outro contexto político. De todo modo, isso não parece ter implicações diretas sobre as potencialidades ético-marxistas de sua filosofia, especialmente porque não existem evidências palpáveis de quão diversas seriam as publicações blochianas caso não houvesse as pressões partidárias daquele período. Quanto a isso, concordamos com Dietschy (1988, p. 73-78), quando este sugere que, apesar da grande probabilidade de algumas citações a Marx e Lenin terem sido forçadas por Bloch, devido ao contexto stalinista repressivo no qual se encontrava, elas sempre estiveram em consonância com o que ele defendia.

9 Parece digno de nota a importância que também a literatura italiana a respeito de Ernst Bloch dá à temática 
o peso que as interpretações latino-americanas dão à questão, ao ponto de causar certo estranhamento por parte de alguns estudiosos estrangeiros ${ }^{10}$. Essa aparente divergência, entretanto, é dissolvida quando assentamos o olhar para as portas de entrada dos textos blochianos na América Latina. Entre os comentadores latino-americanos, é de comum acordo que a entrada de Bloch no continente deu-se indiretamente por uma via teológica, primeiramente, por meio da obra de Jürgen Moltmann ${ }^{11}$, na qual há um apêndice dialogando diretamente com Bloch; e, em seguida, por trabalhos de teólogos, católicos e protestantes, que se dedicaram a fundamentar, por meio da teologia da libertação, lutas políticas que se espalhavam pelo continente a partir de meados dos anos $60^{12}$. A ênfase dada pelos comentadores latino-americanos ao significado ética da filosofia de Bloch, em grande medida,

ética no autor. Nela, semelhantemente ao que ocorre no Brasil e na América Latina, as motivações éticas são tomadas como pressuposto fundamental da filosofia blochiana, ainda que elas possam aparecer via negationis. Seguindo Strano (2013, p. 194), por exemplo, é possível sustentar que, para Bloch, nada é desejado que não seja bom em si mesmo, ou ao menos que não o seja para quem o deseja, e que esse pressuposto se revela como uma medida de juízo para o que não pode ser aceitado como humano, ou seja, aquilo que vai contra a dignidade do ser humano e, portanto, contra a realização de sua essência. Sendo assim, porquanto não seja possível definir aquilo que se deve ser, sabe-se aquilo que não se deve ser, e nisso consistiria a ética da esperança ou ética da utopia em Bloch, mas também, nessa perspectiva, uma ética da dignidade. Nesse mesmo prisma, Bertolino e Coppellotti (1993, p. 382) defendem que a filosofia utópica de Bloch une em si mesma, de maneira indissolúvel, ética e filosofia da história, e que tal união constitui a única busca e invenção do sentido e supõe a negação de tudo aquilo que, teórica e praticamente, impede a construção da meta em direção à qual os seres humanos tendem por meio de uma difícil e contínua mediação entre fins próximos e escopo final. Para um apanhado geral da recepção da obra de Bloch na Itália, veja-se a introdução de: ZACCHINI, Simone. Chimica delle idee musicali: filosofia del suono e música in Ernst Bloch. In: ABBRI, Ferdinando; MATASSI, Elio (org.). Quaderni interdisciplinar - vol 3. Metodologia delle scienze sociali. Musica e Filosofia. Cosenza: Luigi Pellegrini Editore, 2000.

10 Aqui, tomamos a liberdade de considerar nossa experiência pessoal, durante o período de Doutorado Sanduíche, no qual realizamos estudos no Ernst Bloch Zentrum, em Ludwigshafen am Rhein. No período em questão, não só a maioria textos de filosofia sobre o autor relegava a temática ética a um segundo plano no corpus blochiano, como os pesquisadores com os quais conversávamos mostravam surpresa com nossa atenção à questão. De fato, a surpresa muitas vezes parecia mais direcionada ao fato de um filósofo como Ernst Bloch causar interesse aos estudos filosóficos desenvolvidos na América Latina, especialmente no Brasil, do que ao fato de esse interesse concentrar-se sobre a questão ética no autor. Se, como acena Gert Ueding (2016, p. 11), a filosofia de Bloch está intimamente ligada ao seu modo de expressão, isto é, à sua escrita ensaística, portadora de um lirismo particularmente germânico, tentar compreender sua obra a partir de uma tradução latina, que, supostamente, para alguns, inevitavelmente a adulteraria, pode parecer até mesmo como um descalabro para um olhar germânico. Mas não acreditamos que esse seja o caso e, mesmo que a América Latina não tenha sido objeto de atenção para Bloch, é um fato indiscutível que sua filosofia teve e ainda tem impacto, produtividade e importância no continente latino-americano. Com efeito, o modo latino-americano de apropriação das obras de Bloch parece evidenciar, precisamente devido à particularidade de sua visão, aspectos da filosofia blochiana que talvez não sejam tão evidentes em um contexto alemão.

${ }^{11}$ MOLTMANN, Jürgen. Theologie der Hoffnung. Untersuchungen zur Begründung und zu den Konsequenzen einer christlichen Eschatologie. München: Chr. Kaiser Verlag München, 1966.

12 É importante recordar que, embora haja uma influência, "teologia da esperança" e "teologia da libertação" não são sinônimos. Enquanto a primeira é de origem europeia e enfatiza os fundamentos abstratos da teologia, a segunda debruça-se sobre a descoberta das raízes das promessas que sustentam as lutas por libertação (BAUMGARTL, 1998). O brasileiro Rubem Alves é reconhecidamente o precursor da teologia da libertação no continente latino-americano, e sabe-se que a obra responsável por isso, A Theology of Human Hope, originalmente chamava-se Towards a Theology of Liberation, sendo que este fora alterado apenas a pedido da editora, que desejava aproveitar o sucesso da publicação de Moltmann. Sobre isso, veja-se: ALVES, Rubens. Por uma Teologia da Libertação. São Paulo: Fonte Editorial, 2012. 
parece se aproximar muito com o uso feito pelos teólogos de origem europeia que o introduziram no continente ${ }^{13}$

A importância de aspectos teológicos da filosofia blochiana pode ser percebida já na listagem de seus trabalhos que mais eram estudados no continente no período supracitado Thomas Münzer, teólogo da revolução [Thomas Münzer als Theologe Der Revolution], O Princípio Esperança [Das Prinzip Hoffnung] e Ateísmo no Cristianismo [Atheismus im Christentum] - e que até hoje são os textos mais referenciados entre os estudiosos. Se pode causar estranhamento o fato de um "herético", como Bloch, ter influenciado uma onda de literatura teológico-cristã, ele imediatamente se dissipa diante da informação de que, na América Latina, também tal teologia é julgada como herética. Diferentemente do debate teórico que parece ter havido entre os interlocutores cristãos europeus e que continua ocorrendo até os dias de hoje, na América Latina, a filosofia blochiana aliou-se à teologia em seu aspecto mais prático, de ações pastorais. Incitações ao agir prático (político) tendo como meta condições de vida minimamente dignas representaram um pressuposto básico para essa nova teologia que buscava dar um sentido a sua identidade latino-americana.

O hispânico-uruguaio Aínsa (2012), por exemplo, relata que, no fim dos anos 60, Bloch serviu como uma ferramenta para interpretar a diversidade rica e contraditória da América Latina, e, após as frustrações políticas vividas pela juventude no início dos anos 70, a visão antropológica proposta por Bloch teria ajudado a atenuar os efeitos da acelerada demolição dos sonhos diurnos daqueles anos e a projetar, em uma visão integradora da cultura, os fragmentos das ilusões que haviam sofrido. Não obstante a América Latina tenha sido a terra das utopias desde o seu descobrimento ${ }^{14}$, sua história de colonialismo e exploração eurocêntricos teria colaborado para um sentimento de falta de identidade das próprias utopias. Como encontrar uma Heimat sem ao menos saber o que ela pode significar? A filosofia blochiana, com sua proposta de realizar uma hermenêutica da esperança, teria o potencial para

13 Veja-se, por exemplo: MARSCH, Wolf-Dieter. »Eritis sicut Deus«. Das Werk Ernst Bloch als Frage na christiliche Ethik. In.: Kommunität, Berlin, Jan. 1961, H. 17, S. 07-16; MOLTMANN, Jürgen. Die Kategorie Novum in der christlischen Theologie. In: UNSELD, Siegfried (Org.). Ernst Bloch zu eheren. Beiträge zu seinem Werk. Frankfurt am Main: Suhrkamp Verlag, 1965, p. 243-263; PASTOR, Manuel Ureña. Ernst Bloch, Un futuro sin Dios? Madrid: Biblioteca de autores cristianos de La Editorial Católica, 1986.

14 O Brasil foi palco, por exemplo, de uma tentativa de colocar em prática a Civitas Solis de Campanella por meio das missões jesuíticas que lá chegaram logo após o descobrimento. Apesar de terem sido expulsas do país durante o século XVIII, seus ideais continuaram reverberando em outros projetos utópicos. Uma "herança cultural" dessa fase pode ser encontrada, por exemplo, na figura de Antonio Conselheiro, líder da Guerra de Canudos, cuja trajetória messiânica recorda muito aquela de Thomas Münzer. Sobre as matrizes utópicas das missões jesuíticas na América Latina, veja-se: KERN, Arno. Utopias e Missões jesuíticas. Porto Alegre: UFRGS, 1994. Sobre a herança cultural jesuítica de Antonio Conselheiro, veja-se: FAORO, Raymondo. Santo Antônio Conselheiro: jesuíta bronco. Res Severa Verum Gaudium. Porto Alegre, v. 3, n. 2, p. 12-18, abr. 2018. 
ajudar a compreender a função da utopia e os aspectos ainda-não-conscientes dos sonhos latinoamericanos. Em tradução livre do texto de Aínsa (2012, p. 32):

Ele [Bloch] permite estudar a história do imaginário subversivo americano, manifestado através da totalidade de modelos que tentam reduzir a tensão entre ser e dever ser, ou seja, entre realidade e utopia (esperança). Um imaginário que integra todos aqueles comportamentos que transcendem a mera realidade do acontecido, essa multiplicidade de ideias e experiências que configura a "grande enciclopédia da esperança americana" e que outros chamaram de "cemitério das ideologias".

Com uma análise mais focada na realidade brasileira, da Silva (2012), por sua vez, enfatiza o papel que os movimentos de esquerda da igreja católica tiveram na apropriação da filosofia blochiana. Corroborando tal afirmação, Andrade (2012) recorda que, pelo fato de os teólogos da libertação terem identificado o capitalismo como grande alvo de críticas, houve a necessidade de se apoiar em categorias marxistas para compreender a lógica social impregnada na América Latina. Nesse sentido, a abordagem de um pensador herético como Ernst Bloch teria sido fundamental para compreender a pulsão crítica e revolucionária da religião contra o capitalismo $^{15}$.

Tendo isso em vista, mais do que uma via teológica, o terreno propício para o colhimento da filosofia blochiana na América Latina parece estar fortemente relacionado a uma via marxista, indissociável dos pressupostos teóricos da teologia da libertação. Essa pluralidade é evidenciada pelos amplos estudos desenvolvidos por Michael Löwy a respeito do marxismo na América Latina ${ }^{16}$. Segundo o autor, uma série de eventos iniciada no fim dos anos 50 produziu circunstâncias que favoreceram tal convergência. De um ponto de vista mundial, ela teria sido facilitada pela conjuntura histórica de «crise e renovação do catolicismo europeu no pós-guerra, e eleição de João XXIII em 1958 e sua convocação de um novo Concílio, visando o aggiornamento da doutrina e das práticas da Igreja» (LÖWY, 1989, p. 10) ${ }^{17}$, e, ao mesmo

15 De fato, isso continua ocorrendo no Brasil, e o teólogo Leonardo Boff, grande expoente da teologia da libertação, por exemplo, continua sendo um dos grandes divulgadores de Bloch no país, fazendo constantes referências a ele em suas publicações. Boff apoia-se em Bloch, por exemplo, para elaborar uma cristologia para a América Latina (Cf: BOFF, Leonardo. Jesus Cristo Libertador: ensaio de cristologia crítica para o nosso tempo. Petrópolis: Editora Vozes,1972); e indica uma conciliação possível entre Bloch e Hans Jonas no que se refere à relação com a natureza em BOFF, Leonardo. Ecologia: grito da terra, grito dos pobres. São Paulo: Editora Ática, 1995.

16 Veja-se: LÖWY, Michael (Org.). El marxismo en América Latina. Santiago: LOM Ediciones, 2007; LÖWY, Michael. Marxismo e Teologia da Libertação (Coleção polêmicas do nosso tempo, v. 39). Tradução de Myrian Veras Baptista. São Paulo: Cortez: Autores Associados, 1991; LÖWY, Michael. Marxismo e cristianismo na América Latina. Lua Nova, São Paulo, novembro 89, nº 19, p. 05-21.

17 Os acontecimentos do mundo cristão interessam para esse cenário sobretudo considerando que a América Latina é a região do mundo cuja maior parte da população é católica. Dados do Pew Research Center indicam que, em 1970, $92 \%$ da população latino-americana se identificava como católica e 4\% como protestante. Apesar de uma queda substancial, em 2014, mais da metade da população ainda dizia se identificar como católica (69\%), $19 \%$ como protestante e $8 \%$ sem afiliação religiosa. Veja-se: 
tempo, pelo desenvolvimento, de maneira paralela, de «uma crise do marxismo (burocraticamente) institucional, com o $\mathrm{XX}^{\circ}$ Congresso do PCUS e da denúncia do stalinismo» (idem).

Apesar desses fatores terem facilitado uma abertura para as relações entre o cristianismo e o marxismo, possibilitando alguns diálogos, foi na conjuntura latino-americana que se produziram «circunstâncias permitindo um processo muito mais radical de convergência» (idem). Dois aspectos fundamentais teriam colaborado para isso, a começar pelo «desenvolvimento acelerado do capitalismo, uma urbanização intensa e uma industrialização rápida (sob a égide do capital norte-americano) que aprofundam as contradições sociais tanto na cidade quanto no campo» e culminando com a «revolução cubana (1959-60), primeira vitória popular contra o imperialismo na América Latina e primeira revolução socialista no continente - dirigida por forças marxistas de um outro tipo, independentes do comunismo tradicional (de inspiração stalinista)» (idem).

Se a filosofia blochiana da esperança pode ser reconhecida nas incorporações realizadas pela teologia do alemão Jürgen Moltmann, Bloch é também um dos autores mais $\operatorname{citados}^{18}$ por Gustavo Gutiérrez, reconhecidamente o "pai” da teologia da libertação, na obra Teologia de la liberación - Perspectivas $\left[1975^{7}\right]$, e a leitura de Bloch encontrada nela contém boa parte dos elementos que a distinguem das leituras europeias, quais sejam, a ênfase na corrente quente do marxismo e as motivações éticas orientadoras dos sonhos diurnos. A função utópica, por exemplo, tem papel essencial aqui, especialmente quando aliada à fé e à ação política $^{19}$.

Gutiérrez compreende a realidade histórica de maneira complexa e fluída, de modo que a utopia, segundo ele, se volta para o futuro tendo como fundamento dois aspectos que se

$<$ http://www.pewforum.org/2014/11/13/religion-in-latin-america/>. Acesso em julho de 2018.

18 As referências diretas a Bloch dizem respeito especialmente à obra Das Prinzip Hoffnung. Na nota 40, Gutierrez (1975, p. 40) coloca Bloch ao lado de Moltmann para explicar os pressupostos fundamentais da teologia da libertação: «uma concepção dinâmica e histórica do homem orientado definitiva e criadoramente em direção ao futuro, atuando no presente em função do amanhã» e também como a mais séria alternativa ao Ser e Tempo de Heidegger, para a reflexão teológica (nota 59, p. 292). Também são mencionadas Atheismus im Christentum (nota 59, p. 292) como referencia para a crítica à Bultmann, por este ter despojado a fé de toda carga social, e Geist der Utopie, seguida da sugestão de leitura de P. Furter, Utopia e marxismo segundo Ernst Bloch. Tempo Brasileiro, 3 de outubro de 1965, para compreender a noção de anúncio daquilo que ainda-nãoé (idem, p. 311).

$19 \ll$ O termo utopia voltou a ser utilizado, nas últimas décadas, para designar o projeto histórico de uma sociedade qualitativamente diferente e para expressar a aspiração de estabelecer novas relações sociais entre os homens. Numerosos estudos foram e continuam a ser dedicados ao pensamento utópico como elemento dinâmico da evolução histórica da humanidade. Não se deve esquecer, porém, que o que realmente lhe dá validade e evidencia a sua fecundidade é a experiência revolucionária de nosso tempo. Sem a defesa da vida - e a morte de muitos homens que, rejeitando uma ordem social injusta e alienante, se lançam na luta por uma nova sociedade -, a temática da utopia não passaria de uma dissertação acadêmica (GUTIERREZ, 1975, p. 309-310 - tradução nossa), 
exigem mutuamente: a denúncia e o anúncio ${ }^{20}$. Enquanto o primeiro diz respeito à característica revolucionária da utopia (a utopia não é reformista!), indicando que ela significa «necessariamente uma denúncia da ordem existente» (GUTIERREZ, 1975, p. 311 - tradução nossa) e, portanto, tem um olhar retrospectivo (de rejeição daquilo que causa descontentamento de modo insustentável), o segundo diz respeito «àquilo que ainda não é, mas que virá a ser; prenúncio de uma ordem distinta das coisas, de uma nova sociedade» (idem). O anúncio é o campo da imaginação criadora, o campo «que propõe valores alternativos àquilo que é rejeitado» (GUTIERREZ, 1975, p. 311-312 - tradução nossa) ${ }^{21}$. A denúncia e o anúncio se influenciam, um se fazendo em função do outro. Entre ambos está, segundo Gutierrez apropriando-se de Paulo Freire, o tempo da construção, da práxis histórica ${ }^{22}$. Incorporando em sua teoria conceitos também de Paul Ricoeur ${ }^{23}$, Gutierrez afirma que a tese utópica só tem eficiência na medida em que transforma a experiência histórica, sendo enganosa «quando não está articulada de maneira concreta com as possibilidades oferecidas em cada época» (RICOEUR, Táches de l'éducateur politique. Esprit (juillet-août 1965) 91 apud GUTIERREZ, 1975, p. 312 - tradução nossa). A força de um pensamento verdadeiramente utópico, nessa perspectiva, teria o potencial para conduzir a um compromisso em favor de uma nova sociedade, estabelecendo novas metas à ação política ao mesmo tempo em que é verificado por esta.

Gutierrez manifesta a convicção de que a utopia é o ponto de encontro entre fé e política: «a fé e a ação política não se relacionam de maneira correta e fecunda a não ser por meio do projeto de criação de um novo tipo de homem em uma sociedade distinta» (GUTIERREZ, 1975, p. 316-317 - tradução nossa). Sua postura parece sintetizar bem o

20 Devidamente atribuídos por Gutierrez a Paulo Freire, “denúncia" e "anúncio" são conceitos fundamentais da pedagogia do oprimido desenvolvida pelo brasileiro. Veja-se: FREIRE, Paulo. Pedagogia do Oprimido [1970]. Rio de Janeiro: Paz e Terra, $1987^{19}$.

21 Bloch é a referência teórica de Gutierrez para caracterização do anúncio. Ele utiliza como obras, além de $O$ Princípio Esperança (nomeada como a principal obra de Bloch), Espírito da Utopia, e o trabalho de Pierre Furter, Utopia e marxismo segundo Ernst Bloch. Tempo Brasileiro, 3 de outubro de 1965.

22 São patentes as semelhanças entre os pressupostos teóricos que sustentam a pedagogia de Paulo Freire e os fundamentos teóricos da filosofia de Bloch, não obstante não se verifique nenhuma referência direta do primeiro com relação ao segundo. Tal aproximação conceitual é particularmente evidente na Pedagogia da Esperança, cf: FREIRE, Paulo. Pedagogia da Esperança: um reencontro com a Pedagogia do Oprimido. Rio de Janeiro: Paz e Terra, 1992. Sobre a recepção da filosofia blochiana na América Latina e as correspondências entre a teoria de Freire e Bloch, veja-se: HAHN, Paulo. Rezeption von Blochs Sozialutopie im lateinamerikanischen Denken. In: Ernst Bloch: die Dimension der Sozialutopie und ihr Einfluss im lateinamerikanischen Denken sowie die Konzepte Ungleichzeitigkeit und Multiversum als Grundbedingungen für das Verständnis und als Perspektive für einen interkulturellen Dialog. Aachen: Concordia, 2007, p. 51-110.

23 É digno de nota a apropriação de conceitos de Paul Ricoeur, pois sabe-se que ele foi interlocutor de temáticas da filosofia blochiana e, apesar de algumas diferenças, ambos reconhecidamente valorizavam a função utópica. Sobre as convergências entre os pensamentos de Bloch e Ricoeur, veja-se: SARCINELLI, Franco. L'ontologia del non-ancora in Paul Ricoeur ed in Ernst Bloch. Lo Sguardo - Rivista di Filosofia. ISSN: 2036-6558. N. 12, 2013 (II) - Paul Ricoeur: Intersezioni. 
“espírito" que rondava a América Latina entre os anos 60 e 70 . O autor é ciente ${ }^{24}$ de que a mensagem do evangelho, não obstante não ofereça diretamente nenhum programa de ação política e social, por outro lado, como utopia, possui indiretamente significação no plano político e social ${ }^{25}$.

Os escritos de Michael Löwy, entretanto, indicam que antes do surgimento "oficial" da teologia da libertação, já havia manifestações, primeiramente no Brasil e, em seguida, em outras partes do continente, de um "cristianismo da libertação". Nessa perspectiva, a Teologia da Libertação é considerada como a expressão e legitimação de um vasto movimento social que surgiu no início dos anos 60, especialmente motivado pela juventude estudantil cristã. De acordo com Löwy (1989, p. 11-12) a JUC (Juventude Universitária Católica) fora «o primeiro setor dentro da Igreja a conhecer a "tentação marxista"». O ambiente universitário era o meio social no qual as ideias de Marx e seus asseclas tinham maior influência, de modo que «a JUC dos anos 1960-62 representou a primeira tentativa, em todo continente, de desenvolver um pensamento cristão utilizando elementos do marxismo». Apesar desse movimento não ter sido exitoso, influenciou uma série de eventos posteriores envolvendo cristão brasileiros e latinoamericanos. Vale ressaltar que «se tratava não só de um novo discurso, mas também de uma nova prática, no seio do movimento estudantil, no campo da educação popular (MEB) e mais tarde no terreno da ação política (AP)». Além disso,

a doutrina da JUC não tinha caráter teológico, mas representava uma elaboração de leigos sobre a realidade histórica do país. Não era um discurso sobre temas religiosos (cristologia, exegese bíblica, eclesiologia) mas sim uma análise - de inspiração religiosa (católica) - dos problemas econômicos, sociais e políticos do Brasil.

A relação dos assim chamados "jucistas" com Marx não era de idolatria e suas interpretações marxistas não aderiram a nenhum modelo de marxismo já existente no Brasil, como o Partido Comunista Brasileiro (PCB) e seus dissidentes. De fato, a leitura própria do marxismo e da realidade política brasileira levou a JUC a conclusões bem mais radicais que o PCB (na época, alinhado ao populismo governamental) ${ }^{26}$. A postura desses atores sociais sugere

24 Cf. op. cit., nota 125, na qual Gutierrez remete a E. Schillebeeckx in La iglesia, el magistério eclesiástico y la politica, in Dios, futuro del hombre Sígueme, Salamanca, 2a ed. 1970, p. 169.

25 O mesmo papel de "ponto de contato" entre fé e ação política na utopia é identificado por meio de suas leituras de Paul Blanquart e corroborada mais uma vez por Paul Ricoeur ao afirmar que «Apenas a utopia pode dar um enfoque humano para a ação econômica, social e política» (Gutierrez, 1975, p. 317-318 - tradução nossa).

26 Segundo Löwy, (1991, p. 101), fazendo referência a um período um pouco posterior ao surgimento da JUC, o anti-capitalismo da Igreja dos Pobres, «cuja inspiração é, de princípio, religiosa e ética» era «muito mais radical, intransigente e categórico» que aquele dos partidos comunistas, porque era «carregado de repulsa moral». Diz Löwy (idem): «Um exemplo é suficiente para ilustrar esse paradoxo: enquanto o Partido Comunista Brasileiro explicava, nas resoluções do seu VI Congresso (1967), que a "socialização dos meios de produção não corresponde ao nível atual da contradição entre forças produtivas e relações de produção" - em outras palavras, 
uma abertura receptiva seja de referenciais marxistas heterodoxos, seja de referenciais teológicos singulares, cujo ambiente parece propício para acolher uma filosofia como a de Ernst Bloch, mas, especialmente, para interpretar uma tal filosofia de acordo com os anseios e interesses desse contexto específico.

Acreditamos que esse modo reconhecidamente latino-americano de estudar o marxismo e a teologia, com toda a bagagem teórica que orbita sobre esses temas e com as demandas sociais latentes no Brasil e na América Latina, colaboraram para as ênfases dadas aos pressupostos éticos da filosofia blochiana nas interpretações a respeito da obra do autor. Entretanto, a postura blochiana, oposta ao marxismo tradicional e ortodoxo, se concilia harmonicamente com esse marxismo sensível e imerso em questões teológicas, existenciais e coletivas manifestadas na América Latina. De fato, concordando com Löwy (2007, p. 511), «o marxismo e os marxistas não podem ignorar o novo papel do cristianismo como catalizador da libertação das massas oprimidas da América Latina», mas, para tanto, se faz necessário compreender um tipo de prática revolucionária que «extrapola o conceito e não se esgota nas análises estritamente científicas, já que encerra necessariamente dimensões éticas, místicas e utópicas». O marxismo criativo proposto por Bloch instiga precisamente a incorporar tais perspectivas na prática revolucionária, e, com efeito, ao nos debruçarmos sobre o texto blochiano, cabe recordar, junto a Löwy (2007, p. 514), que «marxistas e cristãos possuem mais arquétipos comuns do que supõe nossa vã filosofia».

\section{Referências bibliográficas}

AÍNSA, Fernando. El principio esperanza desde América Latina. In.: ANDRADE, Luis Martínez; MENESES, José Manuel (compiladores). Esperanza y utopia: Ernst Bloch desde América Latina. Zacatecas: Taberna libraría editores, 2012, p. 21-40.

ALBORNOZ, Suzana. Ética e Utopia: ensaio sobre Ernst Bloch [1985]. Porto Alegre: Movimento, 2006.

ANDRADE, Luis Martínez. Principio Esperanza, piedra angular del ecosocialismo. In.: ANDRADE, Luis Martínez; MENESES, José Manuel (compiladores). Esperanza y utopia: Ernst Bloch desde América Latina. Zacatecas: Taberna libraría editores, 2012, p. 75-120.

que o capitalismo deve, em primeiro lugar, desenvolver a economia e modernizar o país - os bispos superiores religiosos da região centro-oeste do Brasil, publicam, em 1973, um documento (O Grito da Terra) cuja conclusão afirma: "É preciso vencer o capitalismo: este é o maior mal, o pecado acumulado, a raiz apodrecida, a árvore que produz todos esses frutos que nós conhecemos: pobreza, fome, doença, morte (...) Por isso, é necessário que a propriedade privada dos meios de produção (as usinas, a terra, o comércio, os bancos) seja superada"».

\begin{tabular}{|l|l|l|l|l|}
\hline Qevista Dialectus & Ano 10 & n. 21 & Janeiro - Abril 2021 & p. 24 - 36 \\
\hline
\end{tabular}


BLOCH, Ernst. Das Prinzip Hoffnung [1959]. Frankfurt am Main: Suhrkamp, 1985.

O Princípio Esperança [1959], Volume III. Tradução de Nélio Schneider. Rio de Janeiro: EdUERJ: Contraponto, 2005, 2006.

DIETSCHY, Beat. Gebrochene Gegenwart: Ernst Bloch, Ungleichzeitigkeit und das Geschichtsbild der Moderne. Frankfurt am Main: Vervuert, 1988.

DUSSEL, Enrique. Ética da Libertação - na idade da globalização e da exclusão. Tradução de Ephraim, F. Jaime. Petrópolis-RJ: Vozes, 2000.

GUTIERREZ, Gustavo. Teologia da Liberación - perspectivas. $7^{\mathrm{a}}$ edição. Salamanca: Ediciones Sígueme, 1975.

LÖWY, Michael (Org.). El marxismo en América Latina. Santiago: LOM Ediciones, 2007. 19, p. 05-21.

Marxismo e cristianismo na América Latina. Lua Nova, São Paulo, novembro 89, nº

MOLTMANN, Jürgen. Theologie der Hoffnung. Untersuchungen zur Begründung und zu den Konsequenzen einer christlichen Eschatologie. München: Chr. Kaiser Verlag München, 1966.

MÜLLER-SCHÖLL, Ulrich; VIDAL, Francesca. Ernst Blochs „,neue Philosophie“ des „Neuen“. Zum Vorwort des Prinzips Hoffnung. In.: ZIMMERMANN, Rainer E. Ernst Bloch: Das Prinzip Hoffnung. Berlin: de Gruyter, 2017, p. 09-34.

MÜNSTER, Arno. Ernst Bloch: filosofia da práxis e utopia concreta. São Paulo: Editora da Universidade Estadual Paulista, 1993.

SCHILLER, Hans-Ernst. Ethik. In.: DIETSCHY, Beat; ZEILINGER, Doris; ZIMMERMANN, Rainer E. (Org.). Bloch-Wörterbuch: Leitbegriffe der Philosophie Ernst Blochs. Berlin: De Gruyte, 2012, p. 102-130.

SCHMIDT, Burghart (Org.). Materialien zu Ernst Blochs »Prinzip Hoffnung«. Frankfurt am Main: Suhrkamp, 1977.

VIEIRA, Antonio Rufino. Marxismo e Libertação: estudos sobre Ernst Bloch e Enrique Dussel. São Leopoldo: Nova Harmonia, 2010.

ZIMMERMANN, Rainer E (Org.). Ernst Bloch: Das Prinzip Hoffnung. Berlin: de Gruyter, 2017. 